\title{
Evaluating Methods of Vibration Exposure and Ride Comfort in Car
}

\author{
Se Jin Park, Murali Subramaniyam \\ Korea Research Institute of Standards and Science, Daejeon, 305-340
}

\begin{abstract}
Objective: This paper studies the method of measuring whole-body vibration in the car and terms associated. Background: Human exposure to vibration can be broadly classified as localized and whole-body vibration. The whole-body vibration affects the entire body of the exposed person. It is mainly transmitted through the seat surfaces, backrests, and through the floor to an individual sitting in the vehicle. It can affect the comfort, performance, and health of individuals. Method: Human responses to whole-body vibration can be evaluated by two main standards such as ISO 2631 and BS 6841 . The vibration is measured at 8 axes - three translations at feet, 3 translations of hip and two translations of back proposed by Griffin. B\&K's sensors used in this study are the 3-axes translational acceleration sensor to measure the translational accelerations at the hip, back and foot. Results: The parameters associated with the whole-body vibration in the car are frequency weightings, frequency weighted root-mean-square, vibration dose values, maximum transient vibration value, seat effective amplitude transmissibility, ride values and ride comfort. Conclusion: Studied the evaluating methods of vibration exposure and ride comfort. Application: Evaluation of whole-body vibration in the car.
\end{abstract}

Keywords: Ride values, Ride comfort, SEAT value, RMS, Vibration

\section{Introduction}

In recent years, there has been the increase of possibilities in getting exposed to vibration and impact caused by living environment, working environment, and riding environment such as cars, vessels and flights. A comfortable ride is essential for a vehicle to obtain passenger satisfaction (Park et al., 1997, 1998, 2001; Kim et al., 2001; Nahvi et al., 2006). There have been lots of studies attempted to identify factors contributing to the ride quality (Parsons and Griffin, 1983; Pardko and Lee, 1966; Reed et al., 1991; Wambold, 1986; Park et al., 1998; Kim et al., 2001). Ride comfort is a very important problem in vehicle design as well as in vehicle judgment (Valasek et al., 2008; Park et al., 1998, 1998a; 2001). Seating comfort is associated with the various factors such as dynamic, postural, visual, sonic, and thermal comfort. Among these types of comfort, one of the principal components of a vehicle environment which can affect passenger's comfort is vibration (Reed et al., 1991; Park et al., 1997, 1998; Paddan and Griffin, 2002).

Vibration transmission to passengers has a large influence on comfort, performance, and health (Griffin, 1990). Vibration also affects passenger's ability to carry out tasks, such as eating, reading and writing. Under more extreme conditions vibration will have psychological and physio-

Corresponding Author: Se Jin Park. Korea Research Institute of Standards and Science, Daejeon, 305-340.

Mobile: +82-10-5406-5450, E-mail:sjpark@kriss.re.kr

Copyright@2013 by Ergonomics Society of Korea(pISSN:1229-1684 eISSN:2093-8462). All right reserved.

(c) This is an open-access article distributed under the terms of the Creative Commons Attribution Non-Commercial License(http://creativecommons.org/licenses/by-nc/3.0/), which permits unrestricted non-commercial use, distribution, and reproduction in any medium, provided the original work is properly cited. http://www.esk.or.kr 
logical effects, such as motion sickness, headaches, and even chronic health effects (Hostens, 2004). Human exposure to vibration can be broadly classified as whole-body and localized vibration. Whole-body vibration is defined as a motion transmitted to the human body as a whole through supporting surfaces, as opposed to vibration directed more locally, such as hand-arm vibration. It is important to under-stand the effects of whole-body vibration, because millions of people expose themselves to it every day while working and commuting (Palmer et al., 2003; Hostens, 2004; Mansfield, 2005). There are literally many publications relating to whole-body vibration. The effects of whole-body vibration on a human body have been a subject of interest at least since the early 20th century (Griffin, 1990; Mansfield, 2005). Whole-body vibration mainly transmitted through the seat surfaces, backrests, and through the floor to an individual sitting in the vehicle (Park et al., 1998). The whole-body vibration can affect the comfort, performance, and health of individuals (Griffin, 1990). The comfort and health relate in many ways. The methods used for health evaluation are mainly based on perception and comfort studies (Mansfield, 2005). Thus the method for evaluating the health effects is the same as for evaluating comfort.

When developing car seats, human health (Kelsey, 1975; McLain and Weinstein, 1994; Necking et al., 1992; Troup, 1978) and comfort (Dupius and Zerlett, 1986; Griffin, 1990; Park et al., 1997, 1998a) are important design considerations. There have been several experimental test methods developed for evaluating seat vibrational comfort (Giacomin and Bracco, 1995; Meier et al., 1998; Staszewski and Giacomin, 1997; Park et al., 2001).

Human responses to whole-body vibration can be evaluated by two main standards such as ISO 2631 (ISO 2631, 1997) and BS 6841 (BS 6841, 1987). The ISO 2631 is to define methods of quantifying whole-body vibration in relation to human health and comfort, the probability of vibration perception, and the incidence of motion sickness. The ISO 2631-1 concerns human exposure to whole-body vibration due to mechanical vibration and shock. The ISO 2631-2 concerns human exposure to whole-body vibration and shock in buildings with respect to the comfort and annoyance of the occupants. The frequency range considered is $0.5 \mathrm{~Hz}$ to $80 \mathrm{~Hz}$ for health, comfort and perception, and $0.1 \mathrm{~Hz}$ to $0.5 \mathrm{~Hz}$ for motion sickness. The ISO suggests vibration measurements in the three translational axes on the seat pan, but only the axis with greatest vibration is used to estimate the vibration severity. The BS 6841 considers a frequency range $0.5 \mathrm{~Hz}$ to $80 \mathrm{~Hz}$. The $\mathrm{BS}$ standard recommends measuring four axes of vibration on the seat and combines them in an evaluation that assesses the vibration severity. It is important to know the method of measuring vibration and terms associated with vibration. This paper studies the whole-body vibration in the car which constitutes one aspect of the physical environment that can cause discomfort to passengers.

\section{Method}

Evaluation of the effects from whole-body vibration requires measurement of the vibration in the form of acceleration. Based on the standards the vibration is measured between a human body and a vibrating platform. Figure 1 shows the experimental setup for measuring the whole-body vibration at the feet, hip and back. The vibration is measured at 8 axes - three translations $\left(\mathrm{X}_{\mathrm{f}}, \mathrm{Y}_{\mathrm{f}}, \mathrm{Z}_{\mathrm{f}}\right)$ at feet, 3 translations $\left(X_{s}, Y_{s}, Z_{s}\right)$ of hip and two translations $\left(X_{b}\right.$, $Z_{b}$ ) of back. Such measuring scheme is based on that proposed 1990 by Griffin, except that four minor axes are omitted. These omitted 4 axes (3 rotations of hip and $y$-translation of the back) showed a small contribution on the ride values (Park et al., 1998). Generally 12-axis measuring system is accepted in the vehicle industry and adopted by

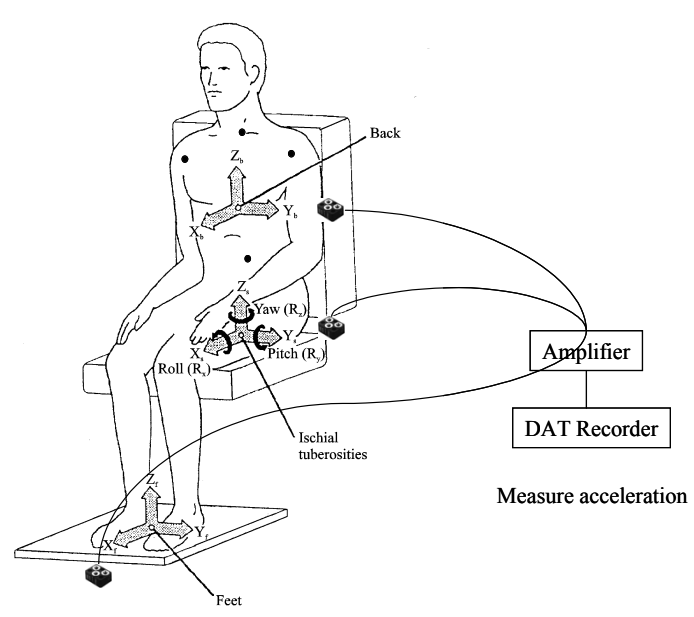

Figure 1. Schematic configuration for the measurement of whole-body vibration (Park et al., 1998) 


\section{BS 6841 .}

There are numerous sensors used in the whole-body vibration studies. B\&K's sensors are most commonly used in the whole-body vibration studies, they are the 3-axes translational acceleration sensor to measure the translational accelerations at the hip, back and foot. The acceleration of the foot is generally measured by B\&K 4326 accelerometer and the accelerations of the hip and back are measured by B\&K 4322 accelerometer. The output signal are amplified through B\&K 8-channel charge amplifier Type 5974 and are recorded with $1 \mathrm{kHz}$ sampling rate by 16-bit digital recorder (Sony DAT 216A) (Park et al., 1998).

\section{Analysis}

\subsection{Frequency weightings}

The manner in which vibration affects health, comfort, perception and motion sickness is dependent on the vibration frequency content (Griffin, 1990). There have been several experimental test methods developed for evaluating seat vibrational comfort. However, the comfort rating was determined by means of the frequency weighting filters defined in ISO 2631 and BS 6841 standards. As ISO 2631 and BS 6841 indicate, the human response to vibration differs by the axes and frequency of the vibration. The weightings have been derived from the study by Griffin (Griffin, 1990).

The subjects' responses are used to determine the equivalent comfort contours. The inverse of such curves form the 'frequency weighting functions'. There are different frequency weightings are required for the different axes of vibration. In order to minimize the number of frequency weightings for axes, some are used for more than one axis with different 'axis multiplying factors'. Therefore, frequency weightings are composed of 4 functions: $\mathrm{W}_{\mathrm{b}}, \mathrm{W}_{\mathrm{c}}, \mathrm{Wd}, \mathrm{W}_{\mathrm{e}}$. The weighting functions and axis multiplying factors used for 8-axis are described in Table 1 and Figure 2.

\subsection{Root-Mean-Square}

The vibration evaluation according to the ISO 2631 shall always include measurements of the weighted root mean square (R.M.S) acceleration. The R.M.S. method is a statistical measure of the magnitude of a varying quantity.
Table 1. Weighting functions and axis multiplying factors (BS 6841, 1987)

\begin{tabular}{c|c|c}
\hline Position & $\begin{array}{c}\text { Weighting function } \\
\left(\mathrm{w}_{\mathrm{i}}\right)\end{array}$ & $\begin{array}{c}\text { Axis multiplying factors } \\
\left(\mathrm{m}_{\mathrm{i}}\right)\end{array}$ \\
\hline $\mathrm{X}_{\mathrm{f}}$ & $\mathrm{w}_{\mathrm{b}}$ & 0.25 \\
$\mathrm{Y}_{\mathrm{f}}$ & $\mathrm{w}_{\mathrm{b}}$ & 0.25 \\
$\mathrm{Z}_{\mathrm{f}}$ & $\mathrm{w}_{\mathrm{b}}$ & 0.40 \\
\hline $\mathrm{X}_{\mathrm{s}}$ & $\mathrm{w}_{\mathrm{d}}$ & 1.00 \\
$\mathrm{Y}_{\mathrm{s}}$ & $\mathrm{w}_{\mathrm{d}}$ & 1.00 \\
$\mathrm{Z}_{\mathrm{s}}$ & $\mathrm{w}_{\mathrm{d}}$ & 1.00 \\
\hline $\mathrm{X}_{\mathrm{b}}$ & $\mathrm{w}_{\mathrm{c}}$ & 0.80 \\
$\mathrm{Z}_{\mathrm{b}}$ & $\mathrm{w}_{\mathrm{d}}$ & 0.40 \\
\hline
\end{tabular}

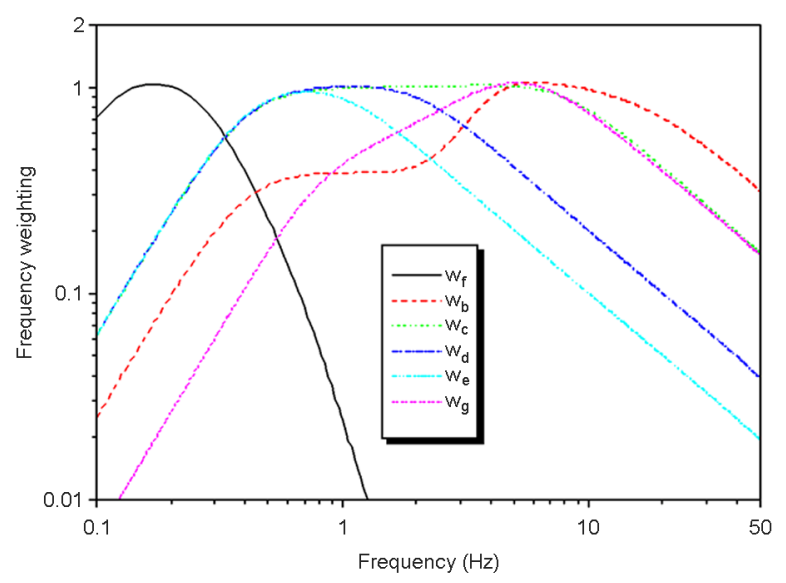

Figure 2. British standard frequency weighting function

It is especially useful for calculating mean of values which are both positive and negative acceleration signal, as the method weights each value as positive. The weighted R.M.S acceleration is expressed in terms of meters per second squared for translational vibrations and radians per second squared for rotational vibrations. ISO 2631 evaluates the vibration transmitted to the body through the supporting surfaces. The ride comfort as per ISO 2631 is evaluated using frequency weighted r.m.s. acceleration and is defined by (Eqn.1):

$$
\operatorname{r.m.s}\left(\mathrm{m} / \mathrm{s}^{2}\right)=\left[\frac{1}{T} \int_{0}^{T} a^{2}(t) d t\right]^{\frac{1}{2}}
$$

Where, a ( $\mathrm{t}$ ) is the frequency-weighted acceleration time 
history; $\mathrm{T}$ is the duration of the measurement, in seconds.

\subsection{Running r.m.s method}

The running r.m.s evaluation method takes into account occasional shocks and transient vibration by use of a short integration time constant. The vibration magnitude is defined as a maximum transient vibration value (MTVV), given as the maximum in time of $a_{w}\left(t_{0}\right)$, defined by the equation (Eqn.2). The maximum transient vibration value (MTVV) is defined as (Eqn.3):

$$
\begin{aligned}
& a_{w}\left(t_{0}\right)=\left[\frac{1}{\tau} \int_{t_{0}-\tau}^{t_{0}}\left[a_{w}(t)^{2}\right] d t\right]^{\frac{1}{2}} \\
& M T V V=\max \left[a_{w}\left(t_{0}\right)\right]
\end{aligned}
$$

Where, $a_{w}(t)$ is the instantaneous frequency-weighted acceleration; $\tau$ is the integration time for running averages; $\mathrm{t}$ is the time (integration variable); $\mathrm{t}_{0}$ is the time of observation (instantaneous time).

\subsection{Vibration Dose Value (VDV)}

When the motion of a vehicle includes shocks or impulsive velocity changes, the VDV is considered more suitable for vibration assessment (BS 6841, 1987; Griffin, 1998; Paddan and Griffin, 2002). It gives a measure of the total exposure to vibration, taking into account the magnitude, frequency, and exposure duration. The VDV reflects the total, rather than the average, exposure to vibration over the measurement period and is considered more suitable when the vibration signal is not statistically stationary (Griffin, 1998; Paddan and Griffin, 2002). It is calculated by the fourth root of the integral with respect to the time of the fourth power of the acceleration after it has been weighted (Eqn.4). The use of the fourth-power method makes the VDV more sensitive to peaks in the acceleration waveform (Griffin, 1990, 1998).

$$
\operatorname{VDV}\left(m / s^{1.75}\right)=\left(\int_{0}^{T}\left[a^{4}(t)\right] d t\right)^{\frac{1}{4}}
$$

Where, a ( $t)$ is the frequency-weighted acceleration time history, and $\mathrm{T}$ is the period of time over which vibration occurs (BS 6841, 1987; ISO 2631, 1997).

\subsection{Ride value}

The ride quality is essentially a subjective matter and each individual's comfort level may be different for the same vibration. It is, therefore, not easy to represent the ride value as a quantity. However, many researchers have tried to quantify the ride value and developed many ride values. In this study, we evaluate the ride values such as the component ride value, the overall ride value and the seat effective amplitude transmissibility (Parsons and Griffin, 1983; Griffin, 1990; Park et al., 1998; Kim et al., 2001).

\subsubsection{Component ride valve}

As per Griffin 1990, the component ride value is defined as the effective magnitude of vibration at a single point (contact point between the human and the seat) and in a single axis after it has been weighted for frequency and axis according to human sensitivity. To obtain the component ride value, power spectral density is multiplied by weighting function for each axis and integrated, then its square root is multiplied by axis multiplying factor as Eqn. (5). These values enable to evaluate the relative contributions of each axis (Griffin, 1990; Park et al., 1998; Kim et al., 2001).

$$
\begin{aligned}
& \text { Component ride value }_{\mathrm{i}}= \\
& \qquad=m_{i} \times\left[\int P_{i i}(f) w_{i}(f)^{2} d f\right]^{\frac{1}{2}}
\end{aligned}
$$

Where, $\mathrm{m}_{\mathrm{i}}$ is the axis multiplying factor; $\mathrm{P}_{\mathrm{ii}}(\mathrm{f})$ is the power spectral density of each axis; $\mathrm{w}_{\mathrm{i}}$ is the weighting function of the each axis.

\subsubsection{Overall ride valve}

As per Griffin 1990, the overall ride value is defined as the effective magnitude of vibration occurring in one or more axes and input positions after it has been weighted for frequency, axis and input position according to human sensitivity. The overall ride value is evaluated as the 2-norm of the component ride value as Eqn. (6). Since this value gives total vibration level, it is adequate for making simple 
comparisons between vehicles with different suspension and seat, etc. We can say the seat having the highest overall ride value would be expected to be the most uncomfortable seat from the viewpoint of vibration (Griffin, 1990; Park et al., 1998; Kim et al., 2001).

\section{Overall RideValue $=$}

$$
=\left[\sum_{i=1}^{N}\left(\text { Component ride value }_{\mathrm{i}}\right)^{2}\right]^{\frac{1}{2}}
$$

\subsubsection{Seat Effective Amplitude Transmissibility (SEAT) value}

SEAT values is the ratio of the vibration experienced on the top of the seat and the vibration that one would be exposed to when sitting directly on the vibrating floor. SEAT values have been widely used to determine the vibration isolation efficiency of a seat. SEAT values can be used to determine how well a seat attenuates vibration from the floor. SEAT value is defined as the weighted vibration ratio between $Z_{f}$ of the floor and $Z_{s}$ of the hip as Eqn. (7), where $P_{s s}(f)$ and $P_{f f}(f)$ are the seat and the floor acceleration power spectra, and $\mathrm{W}_{\mathrm{b}}$ is the same weighting function in both the numerator and denominator (Griffin, 1990; Niekerk et al., 2003), which is the weighting for vibration on the seat. Even though some studies have used the SEAT value as a predictor for dynamic seat comfort (Van der Westhuizen and Van Niekerk, 2006), it is designed and mainly used for evaluating characteristics of a seat damping. SEAT value greater than 1 means the vibration discomfort has been increased by the seat, SEAT value lower than 1 indicates that the level of vibration is reduced by the seat (or) useful isolation provided by the seat (Griffin, 1990; Park, 1998; Kim, 2001).

$$
S E A T=\left[\frac{\int P_{s s}(f)\left|w_{b}(f)\right|^{2} d f}{\int P_{f f}(f)\left|w_{b}(f)\right|^{2} d f}\right]^{\frac{1}{2}}
$$

vibration, taking into account the sensitivity of the seat occupant to different frequencies. SEAT values less than $100 \%$ indicate isolation or attenuation of vibration. It allows for the comparison of seat performance on a variety of road surfaces (BS 6841, 1987).

Seat-isolation performance was indicated by SEAT values, which can be calculated from the frequency-weighted r.m.s accelerations (Eqn. 8) on the seat surface and seat base, $\mathrm{a}_{\text {seat }}$ and $\mathrm{a}_{\text {base, }}$, respectively (Griffin, 1990).

$$
S E A T_{r . m . s}(\%)=\frac{a_{\text {seat }}}{a_{\text {base }}} \times 100 \%
$$

Current standards recommend that if the input motion contains shocks, the SEAT value is determined using the VDV (Eqn. 9) on the seat surface and seat base, VDVseat, and VDVbase as (BS 6841, 1987; ISO 2631, 1997).

$$
S E A T_{V D V}(\%)=\frac{V D V_{\text {seat }}}{V D V_{\text {base }}} \times 100 \%
$$

\section{Conclusion}

The whole-body vibration can affect the comfort, performance, and health of individuals. This paper studied the method of measuring whole-body vibration in the car and terms associated with vibration. As specified in ISO 2631, the relationship between the ride comfort and whole-body vibration were modeled using frequency weightings and RMS averaging. As of ISO 2631, VDV and the MTVV were used to assess vibration transmitted to the passengers. The ride values such as the component ride value and the overall ride value were evaluated based on acceleration root-mean-square. The seat qualities were investigated with the SEAT value. The ride comfort was quantified using either the RMS or the VDV.

\section{References}

The SEAT value is a measure of how well the transmissibility of a seat is suited to the spectrum of entering 
human exposure to whole-body mechanical vibration and repeated shock, 1987.

Dupius, H. and Zerlett, G., The effects of whole-body vibration, SpringerVerlag, Berlin, 1986

Giacomin, J. and Bracco, R., "An experimental approach for the vibration optimisation of automotive seats", ATA 3rd Int. Conf. on Vehicle Comfort and Ergonomics, Bologna, Italy, March 29-31, 1995.

Griffin, M.J., Handbook of Human Vibration, Acdemic Press, London, 1990.

Griffin, M.J., "A comparison of standardized methods for predicting the hazards of Whole-body vibration and shocks", Journal of Sound and Vibration, 215(4), 883-914, 1998.

Hostens, I., "Analysis of seating during low frequency vibration exposure", Katholieke Universiteit Leuven.

International Organization for Standardization, ISO2631, Mechanical vibration and shock - Evaluation of human exposure to whole-body vibration, 1997.

Kelsey, J.L., "An epidemiological study of the relationship between occupations and acute herniated lumbar intervertebral discs", Int. Journal of Epidemiology, 4(3), 197-205, 1975.

Kim, T.H., Cho, Y.G., Yoon, Y.S. and Park, S.J., "Dynamic Ride Quality Investigation and DB of Ride Values for Passenger and RV Cars", SAE Technical Paper 2001-01-0384, 2001, doi:10.4271/2001-01-0384.

Mansfield, N.J., Human response to vibration, CRC Press, London.

McLain, R.F. and Weinstein, J.N., "Effects of whole body vibration on dorsal root ganglion neurons", Spine, 19(13), 1455-1461, 1994.

Meier, R.C., Otto, N.C., Pielemeir, W.J. and Jeyabalan, V., "The Ford vehicle vibration simulator for subjective testing", Sound and Vibration, 26 -32, May 1998.

Nahvi, H., Nor, M.J.M., Fouladi, M.H. and Abdullah, S., "Evaluating Automobile Road Vibrations Using BS 6841 and ISO 2631 Comfort Criteria", In: 1st Regional Conference on Vehicle Engineering \& Technology, Kuala Lumpur, Malaysia, 3-5 July 2006.

Necking, L.E., Dahlin, L.B., Friden, J., Lundborg, G., Lundstrom, R. and Thronell, L.E., "Vibration induced muscle injury", The Journal of Hand Surgery, 17B (3), 270-274, 1992.

Niekerk, J.L., Pielemeir, W.J. and Greenberg, J.A., "The use of seat effective amplitude transmissibility (SEAT) values to predict dynamic seat comfort," Journal of sound and vibration, 260(5), 867-888, 2003.

Paddan, G.S. and Griffin, M.J., "Effects of seating on exposures to wholebody vibrations in vehicles", J. of Sound and Vibration, 253 (1), 215 $-241,2002$.

Palmer, K.T., Griffin, M.J., Syddal, H.E., Pannett, B., Cooper, C. and Coggon, D., "The relative importance of whole body vibration and occupational lifting as risk factors for low-back pain", Occup Environ Med, 60(10), 715-721, 2003.

Park, S.J. and Kim, C.B., "The Evaluation of Seating Comfort by the Objective Measures", SAE Technical Paper 970595, 1997, doi: $10.4271 / 970595$

Park, S.J., Cheung, W.S., Cho, Y.G. and Yoon, Y.S., "Dynamic Ride Quality Investigation for Passenger Car", SAE Technical Paper 980660, 1998, doi:10.4271/980660.

Park, S.J., Lee, Y.S., Nahm, Y.E., Lee, J.W. and Kim, J.S., "Seating physical characteristics and subjective comfort: Design considerations", $S A E$ Technical Paper. 980653, 1998, doi: 10.4271/980653.

Park, S.J., Min, B.C., Lee, J.K. and Kang, E.S., "Development of the Evaluating System for Ride Comfort and Fatigue in Vehicle", $S A E$ Technical Paper 2001-01-0388, 2001, doi: 10.4271/2001-01-0388.

Parsons, K.C. and Griffin, M.J., "Methods for Predicting Passenger Vibration Discomfort", SAE Technical Paper 831029, 1983, doi: 10.4271/ 831029.

Pardko, F. and Lee, R., "Vibration Comfort Criteria", SAE Technical Paper 660139, 1966, doi: 10.4271/660139.

Reed, M.P., Kakishima, Y., Lee, N.S., Satio, M. and Schneider, L.Y., "An Investigation of Driver Discomfort and Related Seat Design Factors in Extended Driving", SAE Technical Paper 910117, 1991, doi: $10.4271 / 910117$.

Staszewski, W.J. and Giacomin, J., "Application of the wavelet based FRF's to the analysis of non-stationary vehicle vibration", 15th Int. Modal Analysis Conf. IMAC, Orlando Florida, U.S.A., 1997.

Troup, J.D., "Drivers back pain and its prevention", Applied Ergonomics, 9(4), 207-214, 1978.

Valasek, M., Pelikan, J., Ulehla, J., Vaculin, O. and Steinbauer, P., "Experimental verification of correlation between objective and subjective of passenger car vibration comfort", Bulletin of Applied Mechanics, 4(15), 99-101, 2008.

Van der Westhuizen, A. and Van Niekerk, J.L., "Verification of seat effective amplitude transmissibility (SEAT) value as a reliable metric to predict dynamic seat comfort", Journal of Sound and Vibration, 295(3-5), 1060-1075, 2006.

Wambold, J.C., "Vehicle Ride Quality Measurement and Analysis", SAE Technical Paper 861113, 1986, doi: 10.4871/861113.

\section{Author listings}

Se Jin Park: sjpark@kriss.re.kr

Highest degree: $\mathrm{Ph} . \mathrm{D}$

Position title: Director, Division of Convergence Technology, KRISS Areas of interest: Human Factors, Human Vibration, Human Sensibility, Biomechanics, Human Computer Interaction (HCI) 
Murali Subramaniyam: murali.subramaniyam@gmail.com

Highest degree: M.Tech (CIM)

Position title: Research Scholar, Center for Medical Metrology, KRISS

Areas of interest: Biomechanics, DHM, CAD/CAM, Ergonomics,

Human Vibration, Human Factors
Date Received : 2013-07-01

Date Revised :2013-08-02

Date Accepted : 2013-08-06 